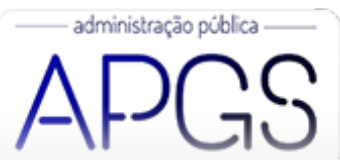

Administração Pública e Gestão Social ISSN: 2175-5787

apgs@ufv.br

Universidade Federal de Viçosa

Brasil

\title{
Sistema de cotas e desempenho: uma comparação entre estudantes cotistas e não cotistas na Universidade Federal de Viçosa
}

Moreira Silva, Bruna Caroline; Silva Xavier, Wescley; de Melo Teixeira da Costa, Thiago

Sistema de cotas e desempenho: uma comparação entre estudantes cotistas e não cotistas na Universidade

Federal de Viçosa

Administração Pública e Gestão Social, vol. 12, núm. 3, 2020

Universidade Federal de Viçosa, Brasil

Disponible en: http://www.redalyc.org/articulo.oa?id=351563312011

Esta obra está bajo una Licencia Creative Commons Atribución-NoComercial-SinDerivar 3.0 Internacional. 


\section{Sistema de cotas e desempenho: uma comparação entre estudantes cotistas e não cotistas na Universidade Federal de Viçosa}

Quota system and performance: a comparison between quota and non-quota students at the Federal University of
Viçosa

Sistema de las cuotas y desempeño: una comparación entre alumnos cotistas y no cotistas en la Universidad Federal de Viçosa

Bruna Caroline Moreira Silva

Redalyc: http://www.redalyc.org/articulo.oa?

Universidade Federal de Viçosa, Brasil

id $=351563312011$

brunacarolms@gmail.com

Wescley Silva Xavier

Universidade Federal de Viçosa, Brasil

wescley@ufv.br

Thiago de Melo Teixeira da Costa

Universidade Federal de Viçosa, Brasil

thiagocosta@ufv.br

Recepción: 22 Octubre 2018

Aprobación: 05 Octubre 2019

\section{Resumo:}

Passados sete anos desde a publicação da Lei no 12.711 (Lei de Cotas), ainda são muitos os questionamentos acerca da legitimidade da mesma, principalmente questionamentos embasados em aspectos meritocráticos e na perda de qualidade das universidades. Diante desse cenário, esse artigo tem como objetivo analisar o desempenho de alunos cotistas e não cotistas, bem como as taxas de evasão universitária. O caso analisado foi o da Universidade Federal de Viçosa, a partir de um estudo quantitativo com uma amostra de 4906 estudantes. Os resultados nos permitem afirmar que estatisticamente não há diferença de desempenho entre cotistas e não cotistas na grande maioria dos cursos. Além disso, identificamos que o desempenho dos estudantes não se correlaciona às notas de entrada na universidade, obtidas a partir da realização do Exame Nacional do Ensino Médio (ENEM). Por fim, verificamos que a taxa de evasão de estudantes cotistas é menor do que de estudantes não cotistas.

Palavras-CHave: Educação pública, ensino superior, Lei de Cotas, ação afirmativa.

\section{Abstract:}

After seven years since the publishing of Federal Law n. 12.711 (Quotas Act), many questions about its legitimacy can be found, mainly those based on meritocratic aspects and on the decreasing of quality in the universities. Therefore, this article aims to analyze the academic performance levels of quota and non-quota students, and the dropout level among both groups as well. The case analyzed here is taken from the Federal University of Viçosa, based on a quantitative research with a sample formed by 4906 students. The findings let us assert that, statistically, there is no a difference between the academic performance level of quota and non-quota students in the vast majority of undergraduate courses. Furthermore, we have found out that the academic performance levels are not correlated with student entrance exam scores, based on the National Secondary Education Examination (ENEM). Finally, we have verified that the dropout level among quota students are lower than non-quota ones.

KEYWORDS: Public education, higher education, Quota Act, affirmative action.

\section{RESUMEN:}

Después de siete años desde la publicación de la Ley Federal n. 12.711 (Ley de las Cuotas), aún podemos encontrar cuestionamientos acerca de la legitimidad de la misma, basados en aspectos de una meritocracia y en la supuesta reducción de la calidad en las universidades. Ante este escenario, este artículo tiene como objetivo analizar el desempeño de alumnos de cuota y los sin cuotas, así como las tasas de evasión de en los agrupamentos. El caso analisado aqui és lo de la Universidad Federal de Viçosa, basado en una investigación cuantitativa con una muestra formada por 4906 estudiantes. Los resultados nos permiten afirmar 
que estadísticamente no hay diferencia de desempeño entre alumnos de cuota y los que no las utilizaron en la gran mayoría de los cursos. Además, identificamos que el desempeño de los estudiantes no se correlaciona con las notas de entrada en la universidad, por medio del Examen Nacional de Enseñanza Secundaria (ENEM). Por último, verificamos que la tasa de evasión de estudiantes de cuota es menor que de estudiantes sin cuotas.

Palabras Clave: Educación pública, educación superior, Ley de Cuotas, acción afirmativa.

\section{INTRODUÇÃO}

Nas últimas duas décadas, as políticas públicas direcionadas ao ensino superior foram objetos de debates, embora estes nem sempre fossem institucionalizados e estruturados. Dentre as mudanças adotadas, a Lei $\mathrm{n}^{\circ}$ 12.711, aprovada em agosto de 2012 e comumente conhecida como Lei de Cotas, talvez tenha sido a mais polêmica. Enquanto política pública pode permitir não apenas a reconfiguração no perfil dos alunos ingressantes no ensino superior público, historicamente elitizado, mas também a possibilidade de uma redistribuição de renda autossustentável, dado que a correlação entre nível de escolaridade e renda é positiva. Tomando esse pressuposto como verdadeiro, seria possível entender um transbordamento dessa política para sanar desequilíbrios sociais e econômicos históricos, emergenciais em um país onde a razão entre o rendimento dos $1 \%$ mais ricos da população e dos 50\% mais pobres é igual a 38,4 (Pesquisa Nacional por Amostra de Domicílios - Pnad Contínua, 2017).

Diante desse quadro, um dos principais argumentos na esfera pública é o de que a formação universitária permite a redução das desigualdades sociais entre os diferentes grupos na sociedade, principalmente quando da inserção no mercado de trabalho (Souza \& Brandalise, 2017), uma vez que esta seria, possivelmente, uma medida de curto prazo e razoavelmente sustentável que assumiria um caráter imediatista frente à baixa qualidade do ensino de base, além de possibilitar a reparação histórica da desigualdade social no país.

Não obstante os possíveis efeitos para além de um perfil de aluno que seja mais representativo da heterogeneidade social encontrada no Brasil, é possível enumerar diversos argumentos contrários às cotas. Dentre os principais, destacam-se a hipotética perda de qualidade no ensino superior, diante do possível desempenho inferior dos alunos cotistas (Santos, 2012); a ameaça à meritocracia, dada a crença de que os estudantes devem alcançar o ensino superior a partir do rendimento apresentado nos processos seletivos, e mais especificamente no caso das cotas raciais, o argumento de que as mesmas causariam o aumento do preconceito de raça (Lima, Neves, \& Silva, 2014). Ademais, há que se considerar a necessária problematização que se impõe a essas políticas, em particular diante da possibilidade de aumento da evasão no ensino superior, dado que a retenção dos alunos cotistas passa por um incremento nos programas de assistência estudantil (Rigo, 2016).

É frente a este quadro que as políticas de redução de desigualdades através da reserva de vagas na educação superior se encontram, pois, se por um lado elas se configuram como possibilidades de criação de uma maior equidade social, por outro esbarram em desafios como a retenção dos alunos e argumentos contrários, ora embasados por vieses meritocráticos de perda de qualidade no ensino e numa suposta igualdade racial.

A hipótese desse trabalho, embebida na visão de mundo dos autores, é caracterizada pela descrença de uma significativa diferença no desempenho acadêmico entre alunos cotistas e não cotistas. Ainda que a mesma se apresentasse quando da entrada dos estudantes no ensino superior, dadas as já conhecidas discrepâncias entre o ensino de base público e o privado, pressupomos que, no decorrer da graduação, cotistas teriam seu rendimento acadêmico igualado aos dos estudantes não cotistas. Em ambas as situações o que propomos é confrontar as premissas objetivas de um argumento cunhado na meritocracia.

A ideia de mérito, objeto de crítica neste trabalho, deve, portanto, dar lugar à ideia das oportunidades às quais os alunos têm acesso. Desse modo, ao problematizar e analisar o rendimento acadêmico dos alunos, esta pesquisa não tem, de forma alguma, o intuito de valorizar a ótica do desempenho, mas justamente o de 
procurar derrubar esse estigma, lançando luz sobre a busca por mais equidade social, pautada numa igualdade de oportunidades.

Diante do contexto supracitado e dos nossos pressupostos acerca do objeto, este artigo tem como objetivo analisar o desempenho de alunos cotistas e não cotistas durante a graduação, aqui representado pelo rendimento acadêmico e a inserção em atividades acadêmicas. Ademais, analisamos também as taxas de evasão de ambos os grupos. Para tal, foram analisados os dados dos estudantes ingressantes na Universidade Federal de Viçosa (UFV), campus sede, localizado na cidade de Viçosa (MG), em seus 45 cursos de graduação, no período de 2013 a 2015, com observações de rendimento que compreendem o intervalo entre o primeiro semestre de 2013 e o primeiro semestre de 2016, contabilizando uma amostra de 4906 estudantes. Em complemento, as análises contemplam 697 questionários aplicados a estudantes de graduação da universidade estudada, desvelando outros elementos acerca da adoção das cotas.

\section{A EDUCAÇÃO NO PROCESSO DE ENFRENTAMENTO DAS DESIGUALDADES}

A sociedade brasileira carrega uma configuração de forte desigualdade social, marcada por uma herança racista e hierárquica, presente desde a colonização até os dias atuais. Essas desigualdades são muitas vezes mascaradas e naturalizadas mesmo por aqueles que estão em situação de segregação. Quanto a essa "naturalização", Souza (2012) defende que a sociedade não consegue discernir claramente as desigualdades causadas pela existência de classes sociais, o que gera uma dominação ainda maior da classe dominante, legitimando a desigualdade.

Fernandes (2008) credita as origens dessa desigualdade, quando discorre acerca do modelo no qual a sociedade colonial brasileira foi baseada, onde havia a superposição do padrão português, "à escravidão de estoques raciais indígenas, africanos e mestiços" (Fernandes, 2008, p. 43). Assim, a figura do cidadão brasileiro que emergiu do fim do período colonial estava diretamente ligada à figura da nobreza, da burguesia, sendo a opinião pública e decisões, em teoria democráticas, concernentes a essas pessoas e não efetivamente à sociedade brasileira como um todo. Excluíam-se assim os brancos pobres, negros, mulatos e indígenas, que continuavam à mercê das escolhas da classe dominante que, por sua vez, apresenta uma grande resistência à mudança e desmedida tentativa de manutenção do poder.

Desse modo, tanto as condições desfavoráveis com que a democracia foi sendo constituída quanto a falta de coerência ideológica fizeram com que uma grande instabilidade fosse construída no regime republicano brasileiro, uma vez que o Estado não conseguia cumprir com a necessidade de educar as massas populares, ainda imbuídas na antiga ordem escravocrata (Fernandes, 2008). É possível elencar dois modelos de educação: Um construído para a burguesia, que objetiva a manutenção do domínio por ela exercido e outro direcionado para os subordinados, no intuito de prepará-los apenas para o mercado de trabalho, sendo, portanto, alienante. "Como resultado, o 'padrão brasileiro de escola superior' não só nasceu completamente 'arcaico', bem como projetou na cena histórica uma influência educacional perene, do tipo arcaizante, impedindo, deste modo, possibilidades de renovação" (Silveira, 2009, p. 6). Para Fernandes (1989), historicamente as universidades têm conservado, no Brasil, a dominação intrínseca àquilo que considera dois modos de educação: Uma educação voltada para a burguesia e a consequente manutenção de uma dominação; de outro lado, a educação focada na preparação para o mercado de trabalho, que aliena e objetifica o trabalhador.

Diante disso, Fernandes (2008), por atribuir um caráter ativo ao educador e por acreditar que a educação tem função política e que cabe a ela ensinar os conteúdos de acordo com a prática, com a realidade, no sentido de ajudar na emancipação humana, defende que "o sistema educacional brasileiro poderá produzir efeitos suficientes para alterar, em um sentido positivo, a articulação do Estado às condições reais da nação" (Fernandes, 2008, p. 108). O sistema educacional poderia então tanto ser palco da manutenção das desigualdades como pode ser palco de mobilidade social, uma vez que "se organizações são criações em vez de entidades naturais, elas podem ser mudadas mediante intervenção social” (Marsden \& Townle, 2001, p. 44). 
A dificuldade de inserção dos grupos negligenciados no sistema de ensino superior público, que tem no histórico de ingressos o predomínio de alunos advindos de uma classe dominante, caracteriza a educação como sendo fortemente marcada pela desigualdade de acesso, sendo mais uma das justificativas de dominação social, econômica e política. Quanto mais alta a vulnerabilidade econômica de uma família, quanto mais baixa a renda dela, menor é o tempo de estudos da mesma e, consequentemente, mais difícil é a possibilidade de se conseguir um emprego com melhores condições de trabalho e mais bem remunerado (Souza \& Brandalise, 2017).

No Brasil, historicamente, as universidades públicas foram ocupadas, em sua maioria, por alunos brancos e com elevada renda familiar. Desse modo, segundo Perroni e Brandão (2009), um ensino público que deveria alcançar todos os setores da sociedade acaba por beneficiar justamente aqueles que sempre estiveram privilegiadamente inseridos, enquanto alunos historicamente marginalizados cessam os estudos cada vez mais prematuramente.

Diante desse cenário, Dubet (2004) confronta a ideia de justiça na educação baseada no êxito diretamente vinculado ao desempenho, de forma objetiva. Segundo o autor francês, encarar essa relação como ponto crítico é necessário, pois ainda que se aceite uma lógica meritocrática e se chegue ao âmbito do "esforço" do aluno para se alcançar determinado desempenho, "a igualdade de oportunidades meritocrática supõe igualdade de acesso" (Dubet, 2004, p. 541). Ou seja, a escola torna-se justa na medida em que todos os alunos passam a ter a possibilidade de nela ingressarem. Ainda que isso ocorra, há uma série de questóes que impedem que se alcance uma redução de desigualdades (de classes sociais, gênero, raça, dentre outras) visto que, a priori, os alunos partiram de classes sociais diferentes, desiguais (Dubet, 2004).

\section{A MERITOCRACIA NO ENSINO SUPERIOR BRASILEIRO}

No Brasil, historicamente, as universidades públicas foram ocupadas, em sua maioria, por alunos brancos e com elevada renda familiar (Perroni \& Brandão, 2009). Esses alunos, pelo alto poder aquisitivo e cultural, estudando em escolas com excelentes estruturas desde os anos iniciais, sempre estiveram em situação de vantagem com relação a alunos negros, indígenas e possuidores de baixa renda familiar. Estes últimos, distantes das facilidades que uma vida privilegiada pode oferecer e muitas vezes tendo, por exemplo, que iniciar no ambiente de trabalho precocemente para ajudar nas despesas de casa, não apresentam, historicamente, as condições materiais necessárias para concorrer com aqueles alunos mais bem preparados, possuidores de tempo, capital cultural e meios adequados para ocupar as poucas vagas de graduação. Desse modo, segundo Perroni e Brandão (2009), um ensino público que deveria alcançar todos os setores da sociedade acaba por beneficiar justamente aqueles que sempre estiveram privilegiadamente inseridos. Logo, o ensino superior público é configurado por um campo não neutro e que, apesar de muitas vezes ser visto como fator de mobilidade social, acaba por ser configurado mais facilmente como mantenedor de classes dotado de reprodução .Bourdieu \& Passeron, 2014).

A má distribuição de escolas bem estruturadas na sociedade mostra-se, assim, diretamente proporcional ao aumento de desigualdades sociais. Perroni e Brandão (2009) defendem que, embora existam instituições educacionais de ensino superior gratuitas e de ótima qualidade, estas têm um caráter muito seletivo, o que faz com que apenas alunos mais bem situados nos extratos sociais consigam ser "recrutados" e configure uma - muitas vezes sutil - eliminação dos mais pobres, uma vez que há diferença até mesmo na proporção de inscritos oriundos de escolas públicas e de escolas particulares de nível básico de ensino nessas instituições de ensino superior.

A diferença nas inscrições que Perroni e Brandão (2009) citam pode ser entendida a partir da teoria de Tarde (1977), que defende que os indivíduos tendem a imitar o comportamento uns dos outros dentro do grupo social no qual estão inseridos. Nesse contexto, antes de um indivíduo tomar uma decisão, ele analisaria as chances de sucesso que outros obtiveram ao tomar a mesma decisão. Se há a percepção de que aquela é uma 
alternativa viável, ele prosseguirá, do contrário, desistirá. Um aluno oriundo de escola pública, portanto, ao ver outros alunos advindos do mesmo grupo social cessando os estudos antes da inserção no ensino superior, tende a ter o mesmo comportamento. Perroni e Brandão (2009) defendem que para além das desigualdades diretas que geram desigualdade de oportunidades estão as ações dos indivíduos que acabam por realimentar as estruturas da desigualdade.

Essa situação é ainda mais potencializada quando essas desigualdades são vistas por um viés meritocrático que iguala "os homens em seu momento de nascimento e estabelecem o mérito e o esforço de cada um como medida para a repartição de bens, recursos e mobilidade social" (Moehlecke, 2004, p. 760), como acima retratado. Helal (2007, p. 387) discorre que "ao se definir como meritocrática, a organização moderna deseja mostrar uma igualdade de oportunidades, e enfatizar uma ideologia - a meritocracia - que privilegia o esforço individual". Essa visão é facilmente legitimada quando, por exemplo, pessoas pertencentes a grupos desfavorecidos conseguem alcançar sucesso, sustentando a ideia de que existem meios para que esse sucesso seja alcançado independente da classe social que elas ocupem, ou seja, a exceção é caracterizada como regra (Barbosa, 2014). Isso problematizado em um contexto onde um grupo dominante ainda se encontra inserido nos espaços de forma privilegiada e, ainda, de maneira histórica e legitimada, acaba sendo apenas mais uma forma de se mascarar desigualdades.

Bourdieu e Passeron (2014) ponderam que as diferentes posições que os alunos ocupam no ambiente escolar revelam-se vantajosas ou desvantajosas porque são cumulativas, uma vez que estão ligadas a todo o histórico familiar: "De todos os fatores de diferenciação, a origem social é sem dúvida aquela cuja influência exerce-se mais fortemente sobre o meio estudantil, mais fortemente em todo caso que o sexo e a idade" (Bourdieu \& Passeron, 2014, p. 27).

É legítimo pensar que, em um contexto educacional, quanto maior o pertencimento do aluno à classe dominante, melhor será o seu desempenho. Ou seja, um contexto em que certos conhecimentos e habilidades são esperados, alunos de classes sociais mais elevadas, que tiveram acesso a uma educação básica de melhor qualidade e, ainda, que possuem capital cultural dessas classes tenham maiores chances de sucesso (Bourdieu, 1992). Desse modo, em um contexto em que a cultura dominante tende a determinar as "regras do jogo", quanto mais o aluno se identificar com a cultura dominante, mais alto será o seu desempenho. Do lado oposto, quanto menos contato um aluno tiver tido com a cultura dominante, mais baixo será o seu rendimento, pois o processo de ensino-aprendizagem está pautado em determinados conhecimentos e comportamentos que facilitam ou prejudicam a aquisição de conhecimento ( Bourdieu \& Passeron, 2014). Essa talvez seja uma das melhores justificativas para a suposição de que alunos cotistas teriam um desempenho acadêmico inferior ao de alunos não cotistas.

Para os indivíduos originários das camadas menos favorecidas, a escola permanece a única via de acesso à cultura, e isso em todos os níveis do ensino; portanto, ela seria a via real de democratização da cultura se não consagrasse, ignorando-as, as desigualdades iniciais em relação à cultura e se não chegasse com frequência - reprovando por exemplo um trabalho escolar por ser muito "escolar" - a desvalorizar a cultura que ela mesma transmite em favor da cultura herdada que não leva a marca reles do esforço e tem, por isso, todas as aparências da facilidade e da graça (Bourdieu \& Passeron, 2014, p. 38).

Logo, Bourdieu e Passeron (2014) criticam veementemente a ideia de "ideologia do dom" ou de mérito individual, mostrando que as aptidões não são naturais, e sim herdadas culturalmente. Esse é mais um argumento de que a ideia de mérito não deve ser usada, se quer, para realizar uma comparação entre cotistas e não cotistas.

A eficácia dos fatores sociais de desigualdade é tamanha que a igualização dos meios econômicos poderia ser realizada sem que o sistema universitário deixasse de consagrar as desigualdades pela transformação do privilégio social em dom ou em mérito individual. Ou melhor, realizada a igualdade formal das chances, a escola poderia pôr todas as aparências da legitimidade a serviço da legitimação dos privilégios (Bourdieu \& Passeron, 2014, p. 45). 
No mesmo sentido, Dubet (2004) critica a ideia de que as sociedades democráticas modernas partem do princípio de que ao conceberem que cada aluno pode obter o sucesso almejado de acordo com o seu desempenho, a escola se torna justa. Como demonstrada acima, essa concepção é há tempos legitimada. Menin, Shimizu, Silva, Cioldi e Buschini (2008) evidenciam essa questão quando investigam quais são os valores considerados mais importantes para estudantes universitários quanto ao sistema de cotas. No discurso dos universitários abordados na pesquisa, os termos esforço, dedicação e responsabilidade de cada estudante foram enumerados como sendo determinantes para o sucesso de cada um.

Segundo essa lógica, quanto maior o "esforço" empreendido pelo aluno para alcançar determinadas habilidades e realizar determinadas ações, melhor será o seu desempenho. Esse ideal meritocrático pode ser mais facilmente entendido se analisado diante da abordagem comportamentalista, que está embasada na ideia do comportamento que o aluno deve ter para que determinadas metas sejam alcançadas. É um processo que se faz, grosso modo, através de estímulos e respostas. É uma abordagem de caráter utilitarista, cujas ações são automatizadas, mecanizadas. Desse modo, o aluno é passivo ao sistema, condicionado a uma estrutura cujo meio exerce facilmente controle sobre ele (Cunha, 2002a). Logo, o alcance de um alto desempenho seria o fim procurado e o processo pelo qual se passou para alcançá-lo pouco importou. Assim, a ideia de manutenção de uma imposição da cultura dominante seria facilmente alcançada e, mais uma vez, a cultura do mérito seria reforçada.

Todavia, ainda que se aceite uma lógica meritocrática e se chegue no âmbito do "esforço" do aluno para se alcançar determinado desempenho, "a igualdade de oportunidades meritocrática supõe igualdade de acesso" (Dubet, 2004, p. 541). Ou seja, a escola se torna justa na medida em que todos os alunos passam a ter a possibilidade de nela ingressarem. Ainda que isso ocorra, há uma série de questões que impedem que se alcance uma redução de desigualdades (de classes sociais, entre sexos, etc.) visto que, a priori, os alunos partiram de classes sociais diferentes, desiguais (Dubet, 2004).

Para se entender melhor como essa lógica do esforço proposta pelo ideal meritocrático funciona no ambiente escolar, será apresentada uma abordagem oposta, a cognitivista. Nessa abordagem o aprendizado seria um modo no qual toda a bagagem cultural, social e pessoal carregada pelo aluno seria valorizada e, sendo assim, determinante para o aprendizado e o desenvolvimento do mesmo, uma vez que, de acordo com essa abordagem, as interações das pessoas com o meio, de acordo com o modo no qual elas processam conceitos e dados a partir de suas vivências, são fundamentais. Portanto, o ponto fundamental do desempenho do aluno estaria no processo e não nos fins, ou seja, a propensão que o aluno apresenta para desenvolver capacidades (Cunha, 2002b). Nessa perspectiva, a padronização do ensino-aprendizagem não seria um meio eficiente de se conseguir um bom desempenho acadêmico. Já o oposto, a utilização e valorização das individualidades, potencializariam a aquisição dos mais diversos conhecimentos, possibilitando a conquista de autonomia suficiente para saber lidar com as adversidades e inovações que aparecessem no decorrer da vida, ou seja, proporcionando uma real emancipação e autonomia intelectual, permitindo ainda uma organização social mais equilibrada (Cunha, 2002b). Se, por um lado, a abordagem cognitivista pode ser vista como ideológica, a abordagem comportamentalista é vista como de extremo utilitarismo.

Desse modo, diante uma sociedade marcada por forte desigualdade entre classes, mesmo que existisse igualdade de acesso ao ambiente escolar, os alunos continuariam imbuídos em uma lógica social desigual. Logo, ainda que se reconheça a meritocracia como princípio básico, a noção de justiça pressuposta por esse modelo já apresentaria uma série de problemas, tornando-o, no mínimo, controverso, pois

O ideal meritocrático consiste em dar a mesma coisa a todos, e sabemos que, no caso da escola, estamos longe disso. Mas esta concepção de justiça será suficiente se considerarmos que as pessoas e os grupos sociais não são iguais diante da escola? Para obter mais justiça, seria preciso, portanto, que a escola levasse em conta as desigualdades reais e procurasse, em certa medida, compensá-las. Esse é o princípio da discriminação positiva (Dubet, 2004, p. 545).

Isso ilustra mais uma vez que o acesso ao ensino de boa qualidade e gratuito não ocorre realmente de forma pública e igualitária. Logo, democratizar as oportunidades de acesso é um meio de tentar romper com 
a enraizada dominação social e cultural das classes altas, além da já referida redução da desigualdade social de maneira sustentável a curto prazo.

Percebe-se que o ambiente escolar é configurado por um alto nível de complexidade, cujo caráter conflitivo é reafirmado a todo momento, configurando-se como um grande desafio quanto a conseguir integrar e articular indivíduos em um contexto criado, em um primeiro momento, para pautar-se na eficiência. Isso se revela ainda mais desafiador por ter como norteadora uma sociedade democrática que, em teoria, preza por princípios como justiça, igualdade, liberdade, participação e que carece de conhecimento que consiga tornar a realidade mais inclusiva e sustentável.

\section{A RESERVA DE VAGAS NO ENSINO SUPERIOR PÚBLICO BRASILEIRO}

Embora muito se defenda que as ações afirmativas tenham sido primeiramente registradas nos Estados Unidos, o primeiro registro que se tem dessas ações ocorreu na Índia, em 1919, quando o jurista, economista e historiador Bhimrao Ramji Ambedkar "propôs, pela primeira vez na história, e em pleno período colonial britânico, a 'representação diferenciada' dos segmentos populacionais designados e considerados como inferiores" (Wedderburn, 2005, p. 314).

Já nos Estados Unidos, local de origem do termo, as ações afirmativas surgiram na década de 1960, pautadas por uma vertente reparatória da questão racial quando as leis segregacionistas vigentes no país começaram a ser eliminadas. Assim, a ideia das ações afirmativas nesse país foi defendida pelo movimento negro, que buscava não só a garantia de leis antissegregacionistas como também a defesa da melhoria das condições de vida da população negra em defesa da igualdade de direitos (Wedderburn, 2005). É possível perceber que o caráter reparatório e o caráter inclusivo das ações afirmativas se cruzam invariavelmente, não podendo ser vistos de maneira dissociada.

No Brasil, os primeiros lampejos de ideias acerca de ações afirmativas surgiram com os movimentos sociais negros na década de 1940. Não obstante a legitimidade das demandas, foi apenas na Conferência de Durban ${ }^{[i]}$, na África do Sul em 2001, que o Estado brasileiro reconheceu a necessidade de se elaborar medidas que visassem o combate ao racismo. A Conferência é vista como marco porque, desde então, o debate acerca dessas ações foi intensificado, de modo que algumas instituições de ensino superior começaram a realizar a reserva de vagas para determinados grupos (Santos, 2012).

No Brasil, o estado pioneiro na aplicação de algum tipo de reserva de vagas para minorias em instituições de ensino superior públicas foi o Rio de Janeiro, em 2002 e 2003, estabelecendo reserva de vagas para alunos oriundos de escolas públicas, para negros e para pessoas com deficiência. Desse modo, foram contempladas a Universidade do Estado do Rio de Janeiro (UERJ) e a Universidade Estadual do Norte Fluminense (UENF).Em 2003, o Mato Grosso do Sul regulamentou a reserva de vagas na Universidade Estadual do Mato Grosso do Sul (UEMS), algo que ocorreu também na Universidade do Estado da Bahia (UNEB), a primeira universidade a regular a reserva de vagas antes da adoção dessa medida pelo próprio estado da federação.

Dentre as universidades federais, o pioneirismo coube à Universidade de Brasília (UnB), em 2004, que propôs a reserva de $20 \%$ das vagas para candidatos negros. Essa ação da UnB foi especialmente polêmica, em razão dos acalorados debates acerca da questão, e por ter sido instaurada uma comissão para checar se os estudantes se enquadravam ou não nas cotas raciais. Ademais, cabe ressaltar o pioneirismo da UEMS ao assegurar a reserva de vagas para indígenas (Santos, 2012).

Após treze anos de tramitação para a criação de uma lei que regulasse a reserva de vagas em instituições públicas de ensino superior (Santos, 2012), a Lei $\mathrm{n}^{\circ} 12.711$ foi aprovada em agosto de 2012, reservando $50 \%$ das vagas para estudantes cotistas (Decreto $\mathrm{n}^{\circ} 7.284,2012$ ). A partir desse percentual destinado a estudantes que tenham estudado integralmente em escolas públicas, outros recortes são feitos para estratos mais específicos, considerando a renda e a raça autodeclarada. 
Como era de se esperar, a Lei no 12.711 surge acompanhada de uma série de complexidades. Argumentos contrários e favoráveis à política de cotas perpassam diversas esferas, como meritocracia, justiça social e perda de qualidade no ensino, além da crença de que a lei seria apenas uma medida paliativa à precariedade do ensino de base nas escolas públicas. Dentre os defensores da política de cotas, destacam-se os argumentos que entendem as cotas como um meio de diminuir desigualdades e possibilitar o aumento das oportunidades de acesso à educação superior para a população (Feres, Daflon, \& Campos, 2012). Assim, as cotas seriam uma forma de redistribuição das oportunidades, visando a inclusão dessa população historicamente vulnerável (Neves \& Lima, 2007), corroborando a ideia de que o sistema de ensino pode ser visto tanto como mantenedor das diferenças entre classes (Souza \& Brandalise, 2017) como na figura de minimizador das mesmas quando viabilizado de forma democrática.

Não obstante os potenciais ganhos sociais com a Lei de Cotas, também são constatados argumentos que vão na direção oposta. Parte desses argumentos diz respeito a um hipotético menor desempenho por parte dos alunos cotistas (Menin, Shimizu, Silva, Cioldi, \& Buschini, 2008), colocando em risco o bom funcionamento e alta qualidade da instituição (Santos, 2012). Isso faz com que a suposição de igualdade de oportunidades, sendo então o esforço, a dedicação e a responsabilidade de cada estudante os determinantes de seu sucesso (Menin et al., 2008). Em complemento, cabe destacar o argumento concernente à defesa da igualdade racial, pautada em aspectos biológicos, em que todos os homens são iguais e, portanto, possuem capacidades iguais para obterem sucesso, desconsiderando as desigualdades sociais históricas que atribuem privilégios de classe (Moehlecke, 2004).

Após a consolidação da Lei Cotas, é possível observar alguns estudos engajados na investigação dos impactos nos Institutos Federais de Ensino Superior (Ifes). Feres, Daflon e Campos (2012), em estudo realizado pelo Gemma, ao analisarem o percentual médio de vagas reservadas para alunos de escolas públicas e para pretos, pardos e indígenas em 2012 e 2013 (último ano antes da Lei de Cotas e primeiro ano da vigência da Lei), concluem o aumento das vagas destinadas a esses grupos. Desse modo, eles apontam que

A lei federal vence, assim, uma resistência histórica das universidades a atribuir cotas específicas para pretos, pardos e
indígenas e a suposição de que as cotas sociais seriam suficientes para a inclusão desses grupos, uma vez que eles pertencem às
classes sociais mais pobres. Como registraram Paiva e Almeida (2010) a partir de depoimentos de gestores de universidades
praticantes de políticas de ação afirmativa, parece haver uma sensibilidade maior entre os membros da comunidade
universitária à questão da pobreza do que à da desigualdade racial, o que frequentemente resulta na opção pelos alunos de
escolas públicas como beneficiários. A Lei no 12.711 vence esse obstáculo" (Fereset al,, 2012, p. 16).

Pinheiro (2014), ao analisar se há diferença de desempenho acadêmico entre alunos cotistas e não cotistas do Centro Tecnológico e do Centro de Ciências Jurídicas e Econômicas da Universidade Federal do Espírito Santo, concluiu que dos quinze cursos analisados, sete apresentaram diferenças de desempenho acadêmico entre cotistas e não cotistas, uma vez que cotistas apresentaram desempenho acadêmico inferior quando comparados aos não cotistas. Esses sete cursos são o curso de Direito e seis cursos de Engenharia. A autora aponta ainda que em todos os cursos que continham matérias de "Álgebra, Cálculo I, Cálculo II e Cálculo III, o rendimento médio apresentava-se muito abaixo do mínimo para a obtenção dos créditos da disciplina" (Pinheiro, 2014, p. 77). Já no curso de Direito, ainda que cotistas apresentassem desempenho acadêmico inferior aos não cotistas, a média não se aproxima da reprovação. Queiroz, Miranda, Tavares e Freitas (2015), ao utilizarem uma amostra de 2418 alunos de 78 cursos ingressantes no primeiro semestre de 2013 na Universidade Federal de Uberlândia (UFU), apontam que não há diferenças estatísticas entre o rendimento de cotistas e não cotistas. $\mathrm{O}$ estudo indicou que "independentemente da forma de acesso, o critério de seleção dos alunos é capaz de escolher os mais bem preparados e garantir a formação com qualidade dos futuros profissionais" (Queiroz, Miranda, Tavares, \& Freitas, 2015, p. 315). Uma hipótese dessa não inferioridade do desempenho dos estudantes cotistas em relação aos estudantes não cotistas pode ser elaborada pelo fator "oportunidade oferecida aos cotistas", de modo que a partir da inserção dos mesmos 
no ensino superior, estes poderiam superar os reconhecidos problemas no ensino de base público, também motivados pela possibilidade de ascender socialmente a partir dos estudos.

Percebe-se, portanto, a complexidade do sistema educacional, que é caracterizado por um campo não neutro, dotado de jogos de poder, que legitimam desigualdades sociais. Diante desse cenário, a Lei de Cotas pode ser encarada como uma ferramenta de auxílio na tentativa de rompimento das históricas desigualdades sociais brasileiras (Feres et al., 2012), mas que deve, contudo, ser estudada, amplamente discutida e aprimorada, no intuito de não negligenciar direitos em um contexto democrático.

Desse modo, analisar como está caracterizado o processo de inserção das cotas no decorrer dos anos é extremamente benéfico por permitir adequações tanto da instituição quanto dos alunos, refutando preconceitos como os listados acerca do desempenho e qualidade do ensino. Outro ponto que carece de atenção diz respeito à articulação de aparatos que busquem não só auxiliar a inserção desses alunos cotistas no contexto acadêmico como o de conseguir visualizar e valorizar diferenças, com o intuito de democratizar não só as oportunidades de acesso, mas também as oportunidades de uma educação de qualidade ${ }^{[i i]}$ para todos os alunos no decorrer do processo.

\section{CONSIDERAÇÕES METODOLÓGICAS}

Este artigo tem como objetivo analisar o desempenho de alunos cotistas e não cotistas durante a graduação, aqui representado pelo seu rendimento acadêmico e pela sua inserção em atividades acadêmicas. $O$ trabalho possui abordagem quantitativa, tendo os dados sido coletados em dois momentos, gerando assim duas bases de dados:

1) Base fornecida pelo pela Diretoria de Registro Escolar da UFV, essa base contém a categoria de ingresso (cotistas ou não cotistas) dos alunos, bem como seus respectivos coeficientes desde o período de entrada até o primeiro semestre de 2016. Cabe destacar que as primeiras observações coletadas são de estudantes que ingressaram em 2013, ano em que a UFV consolidou a disponibilização de $50 \%$ de suas vagas para o sistema de cotas;

2) Base elaborada a partir dos dados obtidos na aplicação de um survey eletrônico aos alunos de graduação da UFV. Sobre o estudo de caso na UFV, a ideia inicial era realizar o estudo em oito universidades federais mineiras. Entretanto, obtivemos retorno apenas da UFV e da Universidade Federal de Lavras (UFLA), sendo os dados desta última incompletos, formado apenas pelos coeficientes de rendimento acumulados, e disponibilizados na etapa final da pesquisa, razóes pelas quais optamos aqui por apresentar somente os dados da UFV.

Desse modo, em um primeiro momento, quando da análise dos dados para verificar se há diferenças estatisticamente significativas entre o coeficiente de alunos cotistas e o coeficiente de alunos não cotistas, o principal parâmetro analisado foi o coeficiente de rendimento semestral e acumulado destes alunos, que foram coletados junto à Diretoria de Registro Escolar da UFV. O coeficiente de rendimento semestral de um aluno é calculado a partir da seguinte fórmula:

$$
C R=\sum(N F \times C) \div \sum C
$$

Sendo:

$\mathrm{CR}=\mathrm{o}$ coeficiente de rendimento;

$\Sigma=$ o somatório;

$\mathrm{NF}=$ a nota final da disciplina;

$\mathrm{C}=$ o número de créditos da disciplina.

Apesar de haver a noção de que o coeficiente de rendimento não necessariamente afere o conhecimento adquirido pelo aluno, optamos aqui por tratar essa variável, dado que a mesma ainda permanece enquanto 
medida objetiva de desempenho dos estudantes. Feita essa ressalva, o coeficiente de rendimento acadêmico é visto aqui como uma proxy ${ }^{[i i i]}$ do desempenho acadêmico do aluno. Visando amenizar essa limitação, foi levantada, através do questionário, a inserção desses alunos em outras atividades acadêmicas (remuneradas ou não remuneradas).

Os coeficientes de rendimento médio de cotistas e não cotistas foram utilizados em quatro análises, a fim de corroborar ou refutar alguns pressupostos contrários à política de cotas:

Pressuposto i: A política de cotas pode reduzir a qualidade do ensino superior, na medida em que alunos cotistas tenham desempenho inferior aos não cotistas. Para tal, buscamos verificar se há diferença estatisticamente significativa entre os coeficientes de alunos cotistas e de alunos não cotistas, bem como se há diferença na evolução desses coeficientes ao longo da graduação;

Pressuposto ii: $\mathrm{O}$ sistema de cotas vai de encontro à meritocracia, uma vez que não privilegia estudantes mais preparados para o ensino superior. Aqui buscamos verificar se há diferença na correlação entre as notas de ingresso (obtidas a partir da realização do Exame Nacional do Ensino Médio [ENEM] e posterior registro das notas na plataforma do Sistema de Seleção Unificada [SiSU]) e o coeficiente de rendimento de cotistas e não cotistas, uma vez que uma correlação mais fortemente positiva indicaria que um bom desempenho no processo seletivo seria acompanhado de um bom desempenho durante o curso, fortalecendo o argumento do mérito;

Pressuposto iii: A política de cotas tende a provocar maior evasão, dado que o hipotético menor desempenho de alunos cotistas e dificuldade de manutenção desses alunos por questões financeiras pode leválos ao abandono do ensino superior.

Após a Análise Exploratória de Dados ter sido realizada para detectar possíveis erros e dados faltosos, bem como retirá-los ou corrigi-los, a base de dados contendo os coeficientes foi constituída por 4906 casos (alunos) dos 45 cursos da universidade. Foram realizados testes de normalidade - análise do histograma da variável e os testes de Shapiro-Wilks e Kolmogorov-Smirnov - no intuito de verificar se há aderência à normalidade da distribuição de cada uma das variáveis (Hair, 2009). A realização desses testes foi imprescindível para que a escolha dos testes de média fosse feita de maneira adequada. A escolha da realização por testes paramétricos, testes ., deve ser feita quando é identificada distribuição normal das variáveis. Em caso de violação dessa distribuição, deve-se utilizar testes alternativos ao ., ou seja, testes não paramétricos (Pestana \& Gageiro, 2008). Nesse caso, para os cursos que não apresentaram aderência à normalidade, foi realizado o teste . de Mann-Whitney de amostras independentes. Cabe destacar, ainda, que 23 cursos apresentaram aderência à normalidade, enquanto 22 deles não apresentaram essa mesma aderência.

Já quanto a verificar se há diferença na correlação entre as notas de ingresso e o coeficiente de rendimento de cotistas e não cotistas, foi utilizado o coeficiente de correlação linear $\mathrm{R}$ de Pearson para um nível de significância de 0,05, que, segundo Pestana e Gageiro (2008), deve ser utilizado quando há o intuito de verificar a correlação entre duas variáveis quantitativas. Cabe destacar que a correlação foi calculada para todos os 4906 estudantes que compóem a amostra, divididos em grupos de cotistas e não cotistas.

Com relação à aplicação do questionário on-line, tendo como universo de pesquisa os 10.196 alunos matriculados na UFV no primeiro semestre de 2016, segundo dados da Diretoria de Registro Escolar da UFV de 2016. Em virtude de toda a população ter sido convidada a responder o questionário, portanto, ter tido chance de participar da pesquisa, a amostra obtida de 728 questionários pode ser classificada como probabilística. Desse modo, dos 728 questionários respondidos pós fase de testes, 31 foram retirados da amostra: 14 deles por não apresentarem respostas para parte significativa das perguntas, 7 por não terem se identificado como cotistas ou não cotistas, informação imprescindível para o objetivo do estudo e, portanto, para a análise dos dados, e outros 7 por serem de estudantes do curso de Licenciatura em Educação no Campo, implementado na UFV em 2014, um ano após o início da Lei de Cotas e, ainda, contar com um processo de seleção diferenciado. Por esses motivos, os dados desse curso também foram excluídos quando da análise dos coeficientes através da base de dados fornecida pela Diretoria de Registro Escolar. 
Com as exclusões devidamente realizadas, restaram 697 questionários a serem analisados, com um nível de confiança de $95 \%$ e margem de erro igual a 3,58\%. Diante desse total, 32,14\% (224 alunos) dos respondentes se identificaram como cotistas e 67,86\% (473 alunos) como não cotistas. Quanto à cor ouraça, 14 (2\% dos respondentes) se autodeclararam amarelos, 364 brancos (52,2\% dos respondentes), 4 indígenas ( $0,6 \%$ dos respondentes), 233 pardos (33,4\% dos respondentes), 74 pretos (10,6\% dos respondentes) e 8 disseram se encaixar na categoria "outros" $(1,1 \%)$. Cabe ressaltar que foram catalogadas repostas advindas de alunos de todos os 45 cursos da universidade. Ademais, com base nos testes de diferença de médias, não foram observadas diferenças significativas entre as notas e no comportamento de outras variáveis entre os diferentes estratos das cotas, o que nos levou a tratar o grupo "cotistas" como homogêneo.

\section{ANÁLISE E DISCUSSÃO DOS RESULTADOS}

Antes de tratarmos das análises propriamente ditas, cabe desatacar alguns aspectos que antecedem a mesma. Após a publicação da Lei de Cotas, foi dada às universidades a possibilidade de adesão imediata ou gradativa ao sistema, ou seja, as mesmas poderiam já em 2013 adotar a reserva de $50 \%$ das vagas para cotistas, ou poderiam ampliar ano a ano esse percentual, até alcançarem os $50 \%$ em 2016, ano limite para tal. No caso da UFV, a escolha foi por reservar $20 \%$ das vagas em 2013, com incremento de $10 \%$ a cada ano, até alcançar os $50 \%$ em 2016. De certa forma, isso poderia provocar alguma distorção nos dados, se considerarmos uma distribuição normal da população. Assim, poderia ser cabível considerar que haveria uma redução de desempenho médio dos cotistas na medida em que o percentual de vagas para esse público aumentasse, dado que a seleção seria "menos rigorosa". Analogamente, seria possível imaginar o efeito contrário para não cotistas, com o aumento de desempenho médio na medida em que percentual de vagas a esse público diminuísse. Entretanto, as análises desagregadas, considerando cada ano, indicaram não haver diferença entre as notas dos grupos quando comparadas ano a ano, ou seja, o percentual de vagas destinadas às cotas e à ampla concorrência não interfere no rendimento dos grupos.

Outro ponto relevante diz respeito à estratificação das cotas, em cinco modalidades, sendo estas:

Modalidade 1: Estudante de escola pública, pretos, pardos, indígenas, com renda familiar bruta mensal igual ou inferior a 1,5 salário mínimo per capita;

Modalidade 2: Estudante de escola pública, com renda familiar igual ou inferior a 1,5 salário mínimo per capita;

Modalidade 3: Estudante de escola pública, pretos, pardos, indígenas, independente de renda;

Modalidade 4: Estudante de escola pública, independente de renda;

Modalidade 5: Ampla concorrência (candidatos que não optarem pela reserva de vagas).

Aos quatro primeiros grupos são destinados $50 \%$ das vagas, sendo a outra metade reservada à ampla concorrência. Como se pode perceber, os grupos contemplados pela política de cotas são heterogêneos e, por consequência, igualmente heterogêneos poderia ser o desempenho desses grupos, inviabilizando algo que aqui denominamos "desempenho dos cotistas". Entretanto, a análise dos dados para cada um dos quatro grupos de cotistas não apresenta diferenças significativas ou variação que possa ser encarada como padrão.

Diante do exposto, apresentamos aqui os dados para os dois grupos, sendo esses não cotistas e cotistas, desconsiderando as peculiaridades dos quatro grupos atendidos pelas políticas de cotas. Ademais, não estabelecemos distinção quanto ao ano de entrada dos estudantes que compõem a amostra, uma vez que diferenças de desempenho não foram encontradas. Após essas considerações, verificamos se há diferença estatisticamente significativa entre os coeficientes de rendimento das categorias de ingresso de cada curso. A escolha de se fazer um teste para cada curso e não apenas um teste abrangendo todos os cursos ocorreu devido ao fato de que quando a Análise Exploratória de Dados (AED) foi realizada, percebeu-se uma grande diferença nas médias de coeficiente entre os cursos, o que poderia provocar distorções nos resultados. Por esse mesmo motivo, na análise dos outliers, optou-se por fazer a retirada dos mesmos através da análise de curso 
por curso. Do mesmo modo, isso se deu pelo fato de que se a escolha de retirada tivesse sido feita a partir da variável coeficiente de rendimento (CRA) completa, os cursos que apresentam média de coeficientes muito baixa ou muito elevada poderiam sofrer uma grande defasagem representativa. Realizadas essas considerações, partimos da seguinte hipótese geral: $\mathrm{H}_{0}$ : A distribuição de coeficientes é a mesma entre as categorias de ingresso (cotistas e não cotistas). $\mathrm{H}_{1}$ : A distribuição de coeficientes não é a mesma entre as categorias de ingresso (cotistas e não cotistas). Os resultados são apresentados na tabela a seguir.

Tabela 1- Desempenho acadêmico de cotistas e não cotistas por curso

\begin{tabular}{|c|c|c|c|}
\hline Curso & $\begin{array}{l}\text { Média de } \\
\text { CRA } \\
\text { Cotistas }\end{array}$ & $\begin{array}{l}\text { Média de } \\
\text { CRA Não } \\
\text { Cotistas }\end{array}$ & $\begin{array}{l}\text { Teste de } \\
\text { Médias }\end{array}$ \\
\hline Administração & 66,744 & 68,37 & Igual \\
\hline Agronegócio & 59,791 & 61,577 & Igual \\
\hline Agronomia & 63,334 & 63,829 & Igual \\
\hline Arquitetura & 77,113 & 77,944 & Igual \\
\hline Bioquímica & 67,373 & 69,307 & Igual \\
\hline Ciência da Computação & 60,037 & 62,962 & Igual \\
\hline $\begin{array}{l}\text { Ciência e Tecnologia de } \\
\text { Laticínios }\end{array}$ & 61,285 & 64,22 & Igual \\
\hline Ciências Biológicas & 69,448 & 73,078 & Igual \\
\hline Ciências Contábeis & 69,142 & 75,261 & Diferente \\
\hline Ciências Econômicas & 64,067 & 64,735 & Igual \\
\hline Ciências Sociais & 71,422 & 73,168 & Igual \\
\hline Comunicação & 77,421 & 78,584 & Igual \\
\hline Cooperativismo & 65,455 & 64,419 & Igual \\
\hline Dança & 71,145 & 71,145 & Igual \\
\hline Direito & 76,088 & 76,598 & Igual \\
\hline Economia Doméstica & 72,746 & 72,412 & Igual \\
\hline Educaçăo Física & 68,342 & 67,373 & Igual \\
\hline Educação Infantil & 69,851 & 72,265 & Igual \\
\hline Enfermagem & 72,3 & 72,242 & Igual \\
\hline $\begin{array}{l}\text { Engenharia Agrícola e } \\
\text { Ambiental }\end{array}$ & 62,943 & 62,921 & Igual \\
\hline Engenharia Ambiental & 65,356 & 66,856 & Igual \\
\hline Engenharia Civil & 70,122 & 70,386 & Igual \\
\hline Engenharia de Agrimensura & 65,1 & 70,638 & Igual \\
\hline Engenharia de Alimentos & 65,009 & 64,936 & Igual \\
\hline Engenharia de Produção & 68,147 & 68,4 & Igual \\
\hline Engenharia Elétrica & 69,67 & 64,302 & Diferente \\
\hline Engenharia Florestal & 66,826 & 65,244 & Igual \\
\hline Engenharia Mecânica & 64,98 & 66,409 & Igual \\
\hline Engenharia Química & 71,624 & 73,756 & Igual \\
\hline Física & 49,37 & 61,622 & Diferente \\
\hline Geografia & 72,026 & 74,563 & Igual \\
\hline História & 74,927 & 77,425 & Igual \\
\hline Letras & 74,396 & 77,172 & Igual \\
\hline Licenciatura em Biologia & 63,776 & 66,165 & Igual \\
\hline Licenciatura em Física & 46,113 & 53,208 & Igual \\
\hline Licenciatura em Matemática & 57,033 & 53,431 & Igual \\
\hline Licenciatura em Química & 55,432 & 63,292 & Diferente \\
\hline Matemática & 49,236 & 65,856 & Diferente \\
\hline Medicina Veterinária & 70,485 & 70,86 & Igual \\
\hline Medicina & 76,312 & 79,106 & Diferente \\
\hline Nutrição & 72,031 & 71,974 & Igual \\
\hline Pedagogia & 83,839 & 83,692 & Igual \\
\hline Química & 61,508 & 64,598 & Igual \\
\hline Secretariado & 73,291 & 77,74 & Igual \\
\hline Zootecnia & 61,285 & 58,861 & Igual \\
\hline
\end{tabular}

Fonte: Dados da Pesquisa. 
Como se pode perceber, apenas seis cursos apresentam diferenças de CRA estatisticamente significativas. Em cinco desses cursos os cotistas possuem uma média estatisticamente menor do que não cotistas, e em um deles cotistas apresentam média maior do que de não cotistas, o curso de Engenharia Elétrica.

Dois pontos são de extrema relevância nestas constatações. O primeiro deles diz respeito à ideia de que estudantes cotistas tendem a ter rendimento acadêmico inferior em relação aos alunos não cotistas, o que dificultaria a manutenção de um alto nível de qualidade supostamente pretendido na formação universitária (Santos, 2012). Desse modo, como aqui apresentado, esse argumento é refutado no universo de pesquisa, uma vez que em grande parte dos cursos a distribuição de coeficientes de cotistas e não cotistas tende a ser estatisticamente a mesma, corroborando os achados de Queiroz et al. (2015). O segundo ponto diz respeito à natureza dos cursos nos quais as notas de alunos cotistas são mais fortemente inferiores que as de não cotistas (Física, Matemática e Licenciatura em Química), sendo estes predominantemente cursos de "ciências duras" da área de exatas. Esse resultado vai ao encontro do encontrado por Pinheiro (2014), que desvela baixo rendimento dos cotistas em disciplinas de álgebra e cálculo.

Além de investigarmos a existência de diferença entre coeficientes de rendimento de alunos cotistas e não cotistas, buscamos também analisar se essa diferença estatística se manifesta no decorrer do curso, comparando os coeficientes de rendimento dos grupos a cada semestre. Após analisarmos os dados de todos os cursos e turmas para alunos ingressantes entre 2013 e 2015, não foi detectado nenhum padrão que nos permitisse criar inferências com relação a possíveis diferenças de evolução das notas dos dois grupos no decorrer do curso. Assim, também não é possível afirmar que há melhoria ou queda de desempenho de um dos grupos, mas apenas que as notas desses dois grupos tendem a caminhar "juntas” no decorrer da graduação. Ademais, cabe destacar que, mesmo sendo necessariamente inferior a nota de entrada de alunos cotistas, essas diferenças não geram padrões de comportamentos de desempenho diferentes em nenhum momento para a maioria dos cursos, conforme pode ser visto na figura 2 a título de exemplo, que ilustra a evolução dos dados dos alunos ingressos em 2013 do curso de Engenharia Mecânica.

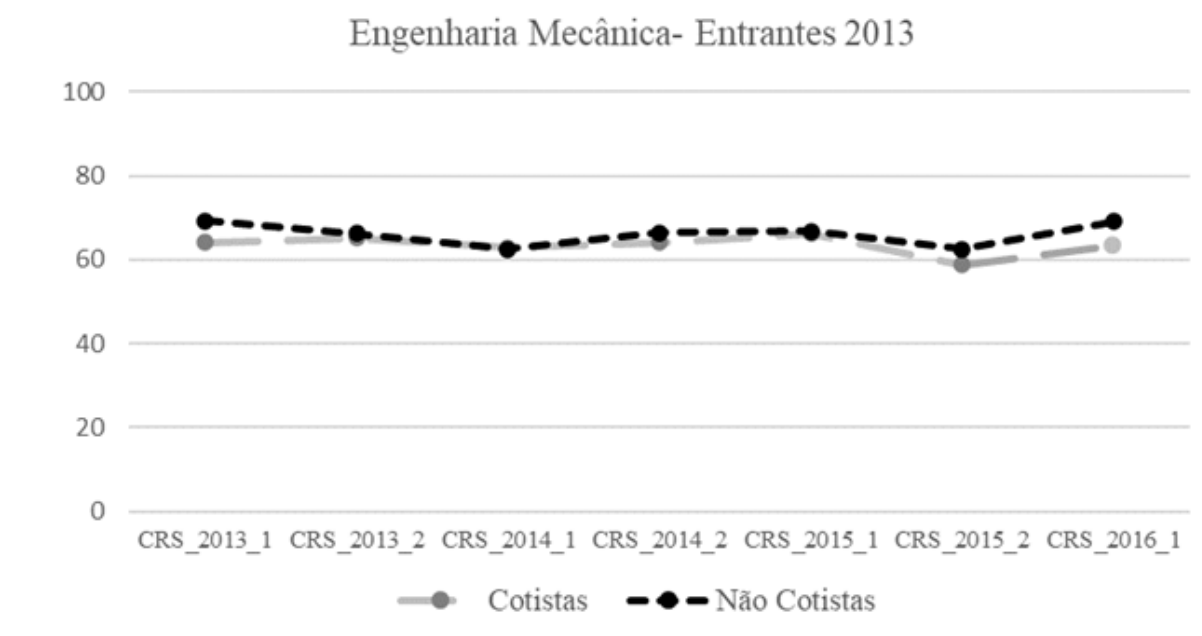

FIGURA 2

Tendência de coeficientes de Rendimento dos Alunos de Engenharia Mecânica Fonte: Dados da Pesquisa.

Ainda quanto às medidas de desempenho que possam ser sinalizadoras de uma perda de qualidade a partir da adoção das políticas de cotas, buscamos analisar a adesão de estudantes cotistas e não cotistas em outras atividades acadêmicas, dados obtidos pela aplicação do survey, visando amenizar uma possível limitação do coeficiente de rendimento como proxy de desempenho acadêmico. A partir das respostas, verificamos que $23,7 \%$ dos cotistas possuem algum tipo de bolsa acadêmica, enquanto entre os não cotistas esse valor é de $23 \%$. A principal diferença encontrada diz respeito aos estágios remunerados, os quais apenas $8,9 \%$ dos cotistas 
afirmaram possuir, enquanto $17,1 \%$ dos não cotistas possuem esse tipo de atividade. Apesar da não diferença no engajamento em atividades de pesquisa, a diferença na adesão aos estágios por parte de cotistas e não cotistas merece ser melhor investigada em estudos futuros, principalmente se considerarmos a relevância dos estágios na formação profissional dos estudantes, bem como ser fonte de recursos financeiros essenciais à permanência dos cotistas na universidade.

Outro aspecto da análise buscou verificar se há correlação entre a nota de ingresso e a nota no decorrer da graduação. A correlação fortemente positiva indicaria a manutenção de um desempenho durante a graduação proporcional ao desempenho na seleção. Assim, ao não privilegiar as melhores notas no processo seletivo, o sistema de cotas iria de encontro à meritocracia, uma vez que não privilegia estudantes mais preparados para o ensino superior.

Por se acreditar que as diferentes formas de acesso podem apresentar diferentes "pontos de corte" quando do ingresso, optamos por utilizar a correlação apenas do que diz respeito às notas de ingresso a partir do ENEM e do SiSU, que abarca $85,1 \%$ dos alunos. Com base nos dados, a ocorrência ou não das correlações entre as notas de ingresso a partir do SiSU e os CRAs de cotistas e não cotistas podem ser verificadas no quadro a seguir. 
Quadro 1 - Correlação entre as notas de ingresso e o CRA dos estudantes

\begin{tabular}{|c|c|c|}
\hline Curso & $\begin{array}{l}\text { Correlação Cotista - } \\
\text { SiSU }\end{array}$ & \begin{tabular}{|l|}
$\begin{array}{l}\text { Correlação Não } \\
\text { Cotista - SiSU }\end{array}$ \\
\end{tabular} \\
\hline Administração & Não & Não \\
\hline Agronegócio & Não & $\operatorname{Sim}(0,393)$ \\
\hline Agronomia & $\operatorname{Sim}(0,341)$ & $\operatorname{Sim}(0,185)$ \\
\hline Arquitetura & Não & Nẫo \\
\hline Bioquímica & Não & $\operatorname{Sim}(0,874)$ \\
\hline Ciência da Computação & Não & $\operatorname{Sim}(0,341)$ \\
\hline Ciência e Tecnologia de Laticínios & Não & Não \\
\hline Ciências Biológicas & $\operatorname{Sim}(0,575)$ & $\operatorname{Sim}(0,312)$ \\
\hline Ciências Contábeis & Nầ & Não \\
\hline Ciências Econômicas & $\operatorname{Sim}(0,390)$ & $\operatorname{Sim}(0,596)$ \\
\hline Ciências Sociais & Não & Não \\
\hline Comunicação & Não & Nẫo \\
\hline Cooperativismo & Não & $\operatorname{Sim}(0,416)$ \\
\hline Dança & $\operatorname{Sim}(0,496)$ & $\operatorname{Sim}(0,512)$ \\
\hline Direito & $\operatorname{Sim}(0,383)$ & $\operatorname{Sim}(0,273)$ \\
\hline Economia Doméstica & Nẫo & Não \\
\hline Educação Física & $\operatorname{Sim}(0,327)$ & $\operatorname{Sim}(0,422)$ \\
\hline Educação Infantil & Năo & $\operatorname{Sim}(0,466)$ \\
\hline Enfermagem & $\operatorname{Sim}(0,452)$ & Nẫo \\
\hline Engenharia Agrícola e Ambiental & Nẫo & Não \\
\hline Engenharia Ambiental & $\operatorname{Sim}(0,621)$ & Não \\
\hline Engenharia Civil & Não & Não \\
\hline Engenharia de Agrimensura & Não & $\operatorname{Sim}(0,335)$ \\
\hline Engenharia de Alimentos & $\operatorname{Sim}(0,349)$ & $\operatorname{Sim}(0,355)$ \\
\hline Engenharia de Produção & $\operatorname{Sim}(0,391)$ & $\operatorname{Sim}(0,351)$ \\
\hline Engenharia Elétrica & Não & Não \\
\hline Engenharia Florestal & Não & $\operatorname{Sim}(0,263)$ \\
\hline Engenharia Mecânica & Não & Não \\
\hline Engenharia Química & Não & $\operatorname{Sim}(0,455)$ \\
\hline Fisica & $\operatorname{Sim}(0,558)$ & $\operatorname{Sim}(0,559)$ \\
\hline Geografia & Não & Nẫo \\
\hline História & Não & Nấo \\
\hline Letras & $\operatorname{Sim}(0,299)$ & $\operatorname{Sim}(0,282)$ \\
\hline Licenciatura em Biologia & Não & Não \\
\hline Licenciatura em Física & Não & Não \\
\hline Licenciatura em Matemática & Não & Não \\
\hline Licenciatura em Química & $\operatorname{Sim}(0,580)$ & Năo \\
\hline Matemática & Não & $\operatorname{Sim}(0,457)$ \\
\hline Medicina & Não & $\operatorname{Sim}(0,288)$ \\
\hline Medicina Veterinária & Não & $\operatorname{Sim}(0,454)$ \\
\hline Nutriçẫo & Não & Năo \\
\hline Pedagogia & $\operatorname{Sim}(0,275)$ & $\operatorname{Sim}(0,390)$ \\
\hline Química & $\operatorname{Sim}(0,410)$ & $\operatorname{Sim}(0,368)$ \\
\hline Secretariado & Não & Nẫo \\
\hline Zootecnia & $\operatorname{Sim}(0,401)$ & Não \\
\hline Total: & $16 \operatorname{sim} 29$ não & $23 \operatorname{sim} 22$ não \\
\hline
\end{tabular}

Fonte: Dados da Pesquisa.

Desse modo, pode-se perceber que não há um padrão a ser detectado pelas correlações, visto que não há grande discrepância de números que possuem ou não possuem correlação entre cotistas e de não cotistas, embora esse último grupo apresente correlação em um maior número de cursos. Ademais, mesmo nos casos em que foram encontradas correlações, é possível perceber que as mesmas não são elevadas. Em linhas gerais, isso sugere que a nota de ingresso dos estudantes não determina o desempenho no decorrer da graduação, independentemente do grupo analisado. 
Por fim, outro ponto de grande discussão diz respeito à retenção dos alunos cotistas na universidade, claramente por duas razões: $\mathrm{O}$ desestímulo por um hipotético baixo rendimento nos cursos e a impossibilidade econômica de manutenção. Do total dos 4906 estudantes que compõem a amostra, 68,7\% permanecem matriculados em situação normal, sendo o percentual de abandono dos cursos igual a 12\%. Já a análise desagregada dos dados indica que a hipótese de maior evasão por parte de alunos costas é refutada, sendo a taxa de abandono desses de $9,4 \%$, enquanto a evasão de estudantes não cotistas é $13,5 \%$.

Outro ponto relevante é o percentual de estudantes desligados dos cursos, algo que geralmente é consequência do baixo desempenho acadêmico. Aqui, novamente, a recorrência é menor entre estudantes cotistas $(6,8 \%)$ em relação aos não cotistas (9\%). Por fim, cabe destacar a diferença percentual de estudantes cotistas e não cotistas em intercâmbio, que pode ser explicada pelo esforço financeiro necessário a esse tipo de atividade. Os dados reforçam a necessidade de programas de financiamento público a atividades dessa natureza, sobretudo a estudantes em maior vulnerabilidade social.

Quadro 2 - Situação dos alunos cotistas e não cotistas

\begin{tabular}{|l|l|l|}
\hline \multirow{2}{*}{ Situação Aluno } & \multicolumn{2}{|l|}{ Modo de Ingresso } \\
\cline { 2 - 3 } & Cotas & $\begin{array}{l}\text { Ampla } \\
\text { concorrência }\end{array}$ \\
\hline Abandono & $9,40 \%$ & $13,50 \%$ \\
\hline Afastamento/Trancamento & $0,90 \%$ & $0,90 \%$ \\
\hline Conclusão & $0,60 \%$ & $2,10 \%$ \\
\hline Desligamento & $6,80 \%$ & $9,00 \%$ \\
\hline Intercâmbio & $0,30 \%$ & $0,60 \%$ \\
\hline $\begin{array}{l}\text { Mudança de } \\
\text { Curso/Transferência }\end{array}$ & $8,50 \%$ & $8,10 \%$ \\
\hline Normal & $73,50 \%$ & $65,90 \%$ \\
\hline Total & $100,00 \%$ & $100,00 \%$ \\
\hline
\end{tabular}

Fonte: Dados da Pesquisa. Elaborado pela autora.

Uma hipótese para a maior permanência nos cursos diz respeito à possibilidade de alunos cotistas encararem a entrada numa universidade federal como possibilidade imediata de ascensão social, considerando o contexto econômico de parte significativa das famílias desses estudantes. Reforça-se aqui a necessidade de estudos que se debrucem sobre essa questão, a fim de investigarem as razões dessa maior permanência.

Consideramos que os resultados aqui trazidos são relevantes, em particular, quando pensamos que esse é um contexto onde a meritocracia é utilizada como medida apriorística de desempenho. Essa justificativa acaba não apenas por maquiar desigualdades, mas também por legitimá-las, pois uma interpretação rasa sugeriria que, como cotistas estão angariando desempenho acadêmico semelhante a não cotistas, mesmo que com uma base de ensino muitas vezes inferior em relação às de não cotistas, é o esforço, dedicação e responsabilidade de cada estudante que determinaria seu sucesso (Menin et al., 2008). Isso poderia ser justificado pelo fato de que cotistas estariam apenas "correndo atrás do prejuízo" para alcançar notas através do mérito. Entretanto, como visto no referencial, a ideia de mérito não deve ser utilizada, sendo que essa situação deve ser pensada por outra perspectiva, considerando que, se cotistas muitas vezes precisam se esforçar mais em atividades acadêmicas, isso faz com que eles tenham menos tempo para participar de atividades não acadêmicas e igualmente importantes para o crescimento pessoal e bem-estar.

\section{CONSIDERAÇÕES FINAIS}

O presente artigo teve como objetivo analisar o desempenho de alunos cotistas e não cotistas durante a graduação, aqui representado pelo rendimento acadêmico e pela inserção em atividades acadêmicas. Ademais, 
analisar os índices de evasão e permanência desses mesmos estudantes na universidade. Este trabalho se mostra relevante na medida em que busca investigar e, a partir dos resultados, contrapor um conjunto de argumentos contrários à política de cotas.

É importante ressaltar que para nós, autores deste trabalho, a legitimidade das cotas ultrapassa qualquer questão ligada ao rendimento acadêmico dos estudantes cotistas, por se tratar não apenas de uma política de educação para o ensino superior, mas de uma política de redução da desigualdade social que historicamente passa pelo caráter elitista das universidades públicas. Em suma, buscamos aqui utilizar das mesmas armas daqueles que combatem a política de cotas para, diante dos resultados, afirmar que mesmo sob a ótica utilitarista do desempenho, não há razoabilidade para um posicionamento contrário às mesmas.

Exploramos neste trabalho o engajamento dos estudantes em atividades acadêmicas. Analisamos também a possibilidade de diferença estatisticamente significativa entre os coeficientes de alunos cotistas e de alunos não cotistas, bem como se há diferença na evolução desses coeficientes ao longo da graduação. Do mesmo modo, investigamos se há correlação entre a nota de entrada e o desempenho dos estudantes durante a graduação, e, por fim, se política de cotas tende a provocar maior evasão, motivada por um hipotético menor desempenho de alunos cotistas e dificuldades financeiras de manutenção por parte destes.

Dos 45 cursos analisados, em apenas seis foram encontradas diferenças estatisticamente significativas entre os coeficientes de rendimento de cotistas e não cotistas. Os resultados encontrados legitimam o pressuposto de Dubet (2004) acerca do deslocamento do caráter meritocrático historicamente impregnado no êxito da entrada do estudante no ensino superior, para a igualdade de oportunidades meritocráticas a partir da igualdade de acesso. Em suma, o caráter meritocrático passa a residir no que cada um faz com a oportunidade concedida, não obstante as inúmeras discrepâncias entre os dois grupos analisados.

Ainda quanto ao desempenho dos estudantes analisados, nos casos em que a discrepância é mais aguda, identificamos cursos de "ciências duras" da área de exatas, corroborando os resultados encontrados por Pinheiro (2014). Essa constatação sinaliza a importância de se investigar as lacunas no ensino e aprendizado dessa área durante o ensino básico e médio nas escolas públicas. Ademais, serve de parâmetro para ações futuras por parte das universidades a fim de sanar as potenciais deficiências que alunos cotistas possam apresentar.

Sobre o engajamento dos alunos em outras atividades acadêmicas, verificamos que não há diferença entre os grupos estudados face à atuação dos mesmos como monitores ou bolsistas de iniciação científica. A principal diferença encontrada diz respeito ao envolvimento com estágios, atividade na qual o percentual de alunos não cotistas é quase o dobro do percentual de cotistas. Sendo o estágio algo relevante para a formação profissional, cabe investigar a razão dessa discrepância. Para estudos futuros, parece plausível investigar quais os aspectos determinantes na obtenção de um estágio, sobretudo os que envolvem o capital social, algo que historicamente é elo mais frágil entre indivíduos de classes mais baixas.

No mesmo sentido, não foi encontrado um parâmetro que permitisse inferir qualquer correlação entre a nota de ingresso e o coeficiente de rendimento acumulado dos alunos. Isso se mostrou especialmente interessante porque refuta, no âmbito do objeto de estudo - a UFV, campus Viçosa - a ideia de que cotistas tenderiam a ter coeficientes de rendimento acadêmico inferior ao de não cotistas e, ainda, que pelo fato de ingressarem com uma carga de conhecimento no ensino básico mais fraca, eles não conseguiriam acompanhar alunos que tiveram, no decorrer da vida, acesso a melhores condições na educação básica.

Indo de encontro com a ideia de igualdade de oportunidades que deve ser sublimada no intuito de invalidar a ideia de mérito, a taxa de evasão de estudantes cotistas mostrou-se inferior em relação a de estudantes não cotistas. Do mesmo modo, verificamos que o percentual de desligamento em decorrência do baixo desempenho acadêmico é inferior entre alunos cotistas. Uma hipótese cabível tanto para a não inferioridade no desempenho acadêmico de cotistas em relação aos não cotistas, como para a menor taxa de evasão dos primeiros em relação aos segundos, é o peso que a possibilidade de se formar em uma universidade pública 
tem para estudantes cotistas, sendo esta uma oportunidade imediata de ascensão social. Todavia, essas são apenas ilações, sendo necessários estudos que investiguem tal questão.

Apesar da já reconhecida limitação dos estudos de caso, entendemos que os resultados aqui encontrados, quando somados a outros achados da mesma natureza, reforçam que os argumentos contrários à política de cotas baseados na hipotética perda de qualidade são falaciosos. Todavia, estamos distantes de esgotar os posicionamentos pautados nesses argumentos, o que torna ainda relevante a incursão de pesquisadores em outros universos amostrais. Para além da métrica, e aqui indo ao encontro do potencial de transformação social que a política de cotas pode representar, muito em breve será necessário avaliar os resultados dessa política na reconfiguração do mercado de trabalho, sobretudo nos aspectos que configuram a absorção dos estudantes cotistas no mesmo. Aqui algumas questões aparecem latentes, como a capacidade de as políticas afirmativas representarem mobilidade social para indivíduos historicamente à margem do ensino superior, principalmente por ainda serem imperativos elementos como o capital cultural (Bourdieu, 1992) na busca por melhores oportunidades no mercado de trabalho.

\section{REFERÊNCIAS}

Barbosa, L. (2014). Meritocracia e sociedade brasileira. Revista de Administração de Empresas. São Paulo, 54(1), 80-85. Bourdieu, P. (1992). O poder Simbólico. Rio de Janeiro: Bertrand Brasil.

Bourdieu, P., \& Passeron, J. C. (2014). Os Herdeiros: os estudantes e a cultura. Trad. Ione Ribeiro Valle e Nilton Valle. Florianópolis: Editora da UFSC.

Cunha, M. V. (2002a). Pavlov, Watson e Skinner - Comportamentalismo e Educação. In: Cunha, M. V. Psicologia da Educação. 2. Ed. Rio de Janeiro: DP\&A, 43-67.

Cunha, M. V. (2002b). Piaget - Psicologia Genética e Educação. In: Cunha, M. V. Psicologia da Educação. 2. Ed. Rio de Janeiro: DP\&A, 69-103.

Demo, P. (2007). Educação e Qualidade. Sa\#o Paulo: Papirus.

Decreto $\mathrm{n}^{\circ}$ 7.284, de 11 de Outubro de 2012. Regulamenta a Lei no 12.711, de 29 de agosto de 2012, que dispóe sobre o ingresso nas universidades federais e nas instituições federais de ensino técnico de nível médio e dá outras providências. Diário Oficial da União, Brasília, DF, 11 de outubro de 2012. Recuperado de: http://www.plana lto.gov.br/ccivil_03/_ato2011-2014/2012/lei/112711.htm.

Dourado, L. F., \& Oliveira, J. F. (2009). A qualidade da educação: perspectivas e desafios. Cad. Cedes, 29(78), 201-215.

Dubet, F. (2004). O que é uma escola justa? Cadernos de pesquisa, 34(123), 539-555.

Feres, J., Jr., Daflon, V. T., \& Campos, L. A. (2012). Ação afirmativa, raça e racismo: uma análise das ações de inclusão racial nos mandatos de Lula e Dilma. Revista de C. Humanas, 12(2), 399-414.

Fernandes, F. (1989). O desafio educacional. São Paulo: Cortez.

Fernandes, F. (2008). Sociedade de classes e subdesenvolvimento. São Paulo: Global Editora.

Hair, J. F., Jr. (2009). Análise Multivariada de Dados. Porto Alegre. Bookman.

Helal, D. H. (2007). O papel da educação na sociedade e organizações modernas: criticando a meritocracia. REAdRevista Eletrônica de Administração, 13(2), 386-408.

Instituto Brasileiro de Geografia e Estatística - IBGE. (2017). Sintese de Indicadores Socias: uma análise das condições de vida da população brasileira. Rio de Janeiro: IBGE, n. 37.

Lima, M. E. O., Neves, P. S. C., \& Silva, P. B. (2014). A implantação de cotas na universidade: paternalismo e ameaça à posição dos grupos dominantes. Revista Brasileira de Educação, 19(56), 141-163.

Marsden, R., \& Townley, B. (2001). Introdução: A coruja de Minerva: reflexões sobre a teoria na prática. In: Clegg, Stewart, Hardy, C., \& Nord, W. (Orgs.). Handbook de estudos organizacionais. São Paulo: Atlas, 2, 31-56.

Menin, M. S. S., Shimizu, A. M., Silva, D. J., Cioldi, F. L., \& Buschini, F. (2008). Representações de estudantes universitários sobre alunos cotistas: confronto de valores. Educação e Pesquisa, 34(2), 255-272. 
Moehlecke, S. (2004). Ação afirmativa no ensino superior: entre a excelência e a justiça social. Educ. Soc., 25(88), 757-776.

Neves, P. S. C., \& Lima, M. E. O. (2007). Percepção de justiça social e atitudes de estudantes pré-vestibulandos e universitários sobre as cotas para negros e pardos nas universidades públicas. Revista Brasileira de Educação, $12(34), 1-23$.

Perroni, J., \& Brandão, A. (2009). Seleção ou Exclusão: difícil acesso a instituições públicas de ensino. Educação \& Realidade, 34(1), 65-81.

Pestana, M. H., \& Gageiro, J. N. (2008). Análise de dados para ciências sociais: A complementariedade do SPSS. Lisboa: Sílabo.

Pinheiro, J. S. S. P. (2014). Desempenho acade\#mico e sistema de cotas: um estudo sobre o rendimento dos alunos cotistas e na\#o cotistas da Universidade Federal do Espirito Santo. Dissertação (Mestrado) - Universidade Federal do Espírito Santo, Vitória.

Queiroz, Z. C. L. S., Miranda, G. J., Tavares, M., \& Freitas, S. C. (2015). A lei de cotas na perspectiva do desempenho acadêmico na Universidade Federal de Uberlândia. Rev. bras. Estud.pedagog. (online), 96(243), 299-320.

Rigo, J. S. (2016). Percursos de Formação de Estudantes de Licenciatura Noturna na UFV: ENEM, SiSU e Evasão. Dissertação (Mestrado) - Universidade Federal de Viçosa, Viçosa.

Santos, J. T. (2012). Ações afirmativas e educação superior no Brasil: um balanço crítico da produção. Revista bras. Est.pedag., 93(234), 401-422.

Silveira, Z. S. (2009). A universidade brasileira e o papel do intelectual em Florestan Fernandes. Colóquio Internacional Marx e Engels, 6., 2009, Campinas. Anais... Campinas: Unicamp, 1-11.

Souza, A. C., \& Brandalise, M. A. T. (2017). Política de cotas e democratização do acesso ao ensino superior: a visão dos implementadores. Revista Internacional de Educação Superior, 3(3), 515-538.

Souza, J. (2012). Os batalhadores brasileiros. Nova classe média ou nova classe trabalhadora? Belo Horizonte: Editora UFMG.

Tarde, G. (1977). O que é sociedade? In: Birnbaum, P., \& Chazel, F. Teoria Sociológica. São Paulo: Hucitec-Edusp, 17-18.

Wedderburn, C. M. (2005). Do marco histórico das políticas públicas de ações afirmativas - perspectivas e considerações. In: Santos, Sales A. (org.). Ações afirmativas e combate ao racismo nas Américas. Brasília: Ministério da Educação, 307-334.

\section{Notas}

[i]Conferência Mundial de Combate ao Racismo, Discriminação Racial, Xenofobia e Intolerância Correlata.

[ii]Por mais que, idealmente, o termo "educação" já pressuponha, ou pelo menos deveria estar intrinsicamente ligado à qualidade, cabe ressaltar o que queremos dizer quando utilizamos a expressão "educação de qualidade". Demo (2007) aponta que, diferentemente da quantidade, que pressupõe extensão, a qualidade pressupõe intensidade, ou seja, "tem a ver com profundidade, (...) principalmente com participação e criação. Está mais para o ser do que para o ter” (Demo, 2007). Nesse sentido, quando utilizamos o termo "educação de qualidade", fazemos no intuito de indicar uma educação que não apenas tenha sido dada ao aluno de modo com que esse venha a possuir um diploma. Utilizamos esse termo com a finalidade de caracterizar uma educação que vise muito mais do que apenas apresentar conteúdos que culminarão no recebimento de um diploma. Uma educação de qualidade seria aquela que desperta a consciência do aluno enquanto ser, no sentido de desenvolver uma consciência crítica que permita com que ele se torne sujeito criador de oportunidades, ou seja, um aluno que consiga se emancipar de tal forma que consiga se reconhecer enquanto um sujeito ativo. Para tal, há a necessidade de as escolas disporem de profissionais aptos para ocupar posições de educadores, tais como professores bem-formados e bem-remunerados - o que implica, também, cargas horárias comedidas, que permitam aperfeiçoamentos constantes, além de infraestrutura adequada das instalações e todas as condições necessárias para a manutenção dos alunos nesses ambientes. E, ainda, "deve considerar a dimensão socioeconômica e cultural, uma vez que o ato educativo escolar se dá em um contexto de posições e disposições no espaço social (...) de heterogeneidade e pluralidade sociocultural, de problemas sociais que repercutem na escola" (Dourado \& Oliveira, 2009). Cabe ressaltar que aqui destacamos 
Bruna Caroline Moreira Silva, et al. Sistema de cotas e desempenho: uma comparação entre estudante...

apenas o fator "ambiente escolar" para uma educação de qualidade. Não excluímos, de forma alguma, a importância de outros espaços e atores formativos, como a família, a religião, a cultura, dentre outros.

[iii]O termo proxy, nesse caso, é utilizado para designar uma variável que foi utilizada em substituição de uma outra de difícil mensuração.

\section{BY-NC-ND}

